\title{
PIWIL-2 and piRNAs are regularly expressed in epithelia of the skin and their expression is related to differentiation
}

\author{
Johannes Pammer ${ }^{1} \cdot$ Heidi Rossiter ${ }^{2} \cdot$ Martin Bilban $^{3} \cdot$ Leopold Eckhart $^{2} \cdot$ Maria Buchberger $^{2} \cdot$ Laura Monschein $^{1}$. \\ Michael Mildner ${ }^{2}$
}

Received: 10 January 2019 / Revised: 10 January 2020 / Accepted: 26 February 2020 / Published online: 12 March 2020

(c) The Author(s) 2020

\begin{abstract}
PIWI proteins play multiple roles in germline stem cell maintenance and self-renewal. PIWI-interacting RNAs (piRNAs) associate with PIWI proteins, form effector complexes and maintain genome integrity and function in the regulation of gene expression by epigenetic modifications. Both are involved in cancer development. In this study, we investigated the expression of PIWIL-2 and piRNAs in normal human skin and epithelial tumors and its regulation during keratinocyte (KC) differentiation. Immunohistochemistry showed that PIWIL-2 was regularly expressed in the epidermis and adnexal tissue with strongest expression in sebaceous glands. Cell culture studies revealed an association of PIWIL-2 expression with the state of differentiated KC. In contrast, the PIWIL-2 expression pattern did not correlate with stem cell compartments or malignancy. piRNAs were consistently detected in $\mathrm{KC}$ in vitro by next-generation sequencing and the expression levels of numerous piRNAs were regulated during KC differentiation. Epidermal piRNAs were predominantly derived from processed snoRNAs (C/D-box snoRNAs), tRNAs and protein coding genes. Our data indicate that components of the PIWIL-2—piRNA pathway are present in epithelial cells of the skin and are regulated in the context of $\mathrm{KC}$ differentiation, suggesting a role of somatic gene regulation. However, putative roles in the maintenance of stem cell compartments or the development of malignancy in the skin were not supported by this study.
\end{abstract}

Keywords PIWIL2 $\cdot$ Hili $\cdot$ piRNA $\cdot$ ncRNA $\cdot$ Skin $\cdot$ Keratinocyte $\cdot$ Carcinoma

\section{Introduction}

The skin is the largest barrier against various physical, chemical or biological stresses, constituting the first line of defense of the body. This function is dependent on both epidermal and skin adnexal differentiation and maintenance [12]. Whereas the role of gene expression and regulation

Electronic supplementary material The online version of this article (https://doi.org/10.1007/s00403-020-02052-7) contains supplementary material, which is available to authorized users.

Johannes Pammer

johannes.pammer@meduniwien.ac.at

1 Clinical Institute of Pathology, Medical University of Vienna, Währinger Gürtel 18-20, 1090 Vienna, Austria

2 Department of Dermatology, Medical University of Vienna, Vienna, Austria

3 Department of Laboratory Medicine and Core Facility Genomics, Medical University of Vienna, Vienna, Austria during epidermal development has been investigated in detail, the role of small non-coding RNAs other than microRNAs (miRNAs) in the homeostasis of the skin is largely unknown [3].

Small non-coding RNAs regulate gene expression by binding to AGO and PIWI proteins. AGO proteins have been shown to connect to miRNAs and small interfering RNAs (siRNA) and to regulate translation, mRNA degradation and heterochromatin formation. In contrast, PIWI proteins bind to piRNAs with a length of $\sim 26-31$ nucleotides [21].

The function of PIWI proteins and piRNAs in restricting the movement of mobile genetic elements in the germline is well known [21]. The mouse homolog to human PIWIL-2, Mili, has also been shown to bind to piRNAs [1] and has been implicated in transposon control and DNA methylation [25]. In addition, PIWI proteins play important roles in a variety of cellular processes including stem cell selfrenewal, spermatogenesis, RNA silencing, translational regulation and chromatin remodeling [21]. In contrast, the 
significance of piRNA originating outside of transposable elements is to a large extent unknown [20,40].

Small RNAs in the nucleus are involved in histone modification, gene expression and alternative splicing [22, 28], probably by binding to nascent RNA or genomic DNA [19, 28]. Recently, the expression of piRNAs has been demonstrated in different human somatic tissues [32], including the central nervous system and the haematopoietic system [26]. In lower level organisms, piRNAs are presumed to be involved in DNA methylation and histone modification [39]. Accordingly, piRNAs, whose role has been well established in germline maintenance, are now also regarded as posttranscriptional regulators of gene expression in somatic cells [20].

Furthermore, a growing number of studies have demonstrated that several piRNA and PIWI proteins are aberrantly expressed in neoplasias [14]. PIWI proteins are involved in the development of malignancies of squamous epithelia [11, 16] and may be regarded as biomarkers in several entities [15]. PIWIL-2 is essential for the proliferation and escape from apoptosis of a variety of cancer cells [27].

An essential role of miRNAs and long non-coding RNAs in skin wound healing [17] and differentiation [30, 51] has been revealed recently, but a possible role of piRNAs in the skin has not yet been shown. Since PIWIL-2 is known to play a role in the maintenance of germline stem cells as well as in the development of carcinomas [27, 53], we set out to look for a possible role of this protein and piRNAs in the skin. We investigated the expression pattern and possible association of PIWIL-2 with epithelial stem cell compartments and neoplasias. In addition, we demonstrated PIWIL-2 expression in KC cultures and investigated its regulation during $\mathrm{KC}$ differentiation in vitro. The possible binding partners, i.e. piRNAs, were profiled from normal $\mathrm{KC}$ using next-generation sequencing, and their expression was correlated to the differentiation state of $\mathrm{KC}$. Gene targets for differentially expressed piRNAs were identified from a database of non-coding RNA (ncRNA) sequences [5].

\section{Methods}

\section{Ethics statement}

Human material was obtained in compliance with local laws and regulations and the responsible ethics committee has approved all experimental procedures (vote no. 1149/2011: isolation and culture of cells from and analysis of normal human skin biopsy samples; and 1498/2017: Expression und Regulation von PIWI-Proteinen und piRNAs in Epidermis und Hauttumoren). Written informed consent was obtained from the participants. Mice were sacrificed by cervical dislocation according to the animal welfare guidelines of the Medical University of Vienna, Austria. The study was approved by the Ethics Review Committee for Animal Experimentation of the Medical University of Vienna, Austria and the Federal Ministry of Science, Research and Economy, Austria (approval number: BMWF-66.009/0124-II/10b/2010).

\section{Immunohistochemistry}

Surgical specimens were processed according to standard pathological procedures. Immunostaining for PIWIL-2 (moAb D-5, Santa Cuz biotechnology, Heidelberg, Germany) at a dilution of 1:40 was performed on the BenchMark ULTRA Automated IHC/ISH slide staining system (Ventana Medical Systems, Tucson, Arizona, USA) using a universal DAB detection kit after antigen retrieval with ULTRA Cell Conditioning CC1 (Ventana). The staining intensity was graded as negative (less than $3 \%$ of tumor cells reactive), weakly $(<10 \%)$, moderately $(<30 \%)$ or strongly $(>30 \%)$ positive. Staining intensity was assessed by two investigators independently.

\section{Cell culture}

Human primary KCs from abdominal skin were prepared as described previously [13] and cultured under low- $\mathrm{Ca}^{2+}$ conditions $(0.15 \mathrm{mmol} / \mathrm{L})$ in serum-free $\mathrm{KC}$ growth medium-2 (KGM-2, Promocell) at $37{ }^{\circ} \mathrm{C}$ in $5 \% \mathrm{CO}_{2}$. Cells were routinely passaged at a confluence of $60-80 \%$. For differentiation, $\mathrm{KC}$ were cultured at $100 \%$ confluency for 7 days under high $\mathrm{Ca}^{2+}$ conditions (KGM-2 medium with $1.2 \mathrm{mmol} / \mathrm{L}$ $\left.\mathrm{Ca}^{2+}\right)$. HUVECs, HDMECs and A431 cell lines were cultured and stimulated as described previously $[33,34]$.

\section{Western blotting of primary human keratinocytes}

Cells were lysed in 1\% NP-40/PBS supplemented with $1 \mathrm{mM}$ PMSF. After removal by centrifugation of the insoluble debris, the protein concentration of the supernatant was measured by the bicinchoninic acid (BCA) method (Pierce, Rockford, IL). Lysates were subjected to SDS-PAGE in $12 \%$ gels under reducing conditions. Subsequently, the proteins were electroblotted onto a nitrocellulose membrane (Schleicher\& Schuell, Germany) at $0.8 \mathrm{~mA} / \mathrm{cm}^{2}$ for $2 \mathrm{~h}$. The membranes were dried and incubated in blocking buffer (5\% non-fat dry milk in PBS) followed by immune overlay with anti-PIWIL-2 moAb (Santa Cruz, dilution 1:500) or GAPDH moAb (1:2000, Cell Signaling Technology, Cambridge, UK). After washing, bound moAb was detected with HRP-labeled sheep anti-mouse-IgG (Amersham Life Science, UK). The immunoreactions were visualized by chemiluminescence using SuperSignal ${ }^{\mathrm{TM}}$ West Dura Extended Duration Substrate (Thermo Fisher Scientific). 


\section{Western blotting of murine tissue}

Testes and preputial glands were prepared from mice immediately after sacrifice by cervical dislocation, $\mathrm{KC}$ were derived from the tail. The tissues were homogenized by sonication in a buffer that contained $50 \mathrm{mM}$ Tris ( $\mathrm{pH}$ 7.4), $2 \%$ SDS and complete protease inhibitor cocktail (Roche, Mannheim, Germany). Protein concentrations were measured as noted above. For Western blot analysis, $40 \mu \mathrm{g}$ protein was loaded per lane on SDS polyacrylamide gels (ExcelGel SDS, gradient 8-18, Amersham Biosciences). The proteins were electrophoresed, blotted onto a nitrocellulose membrane using the Multiphor II Electrophoresis system (Amersham Biosciences) and stained with Ponceau dye. After removal of the dye by washing, the membranes were incubated at $4{ }^{\circ} \mathrm{C}$ overnight with mouse anti- PIWIL-2 (Santa Cruz, dilution 1:500). Subsequently, sheep anti-mouse IgG (NA931V, GE Healthcare Limited, UK) as secondary antibody conjugated to horseradish peroxidase at a dilution of 1:10,000 was applied. Enhanced chemiluminescence (ECL) reagent (ThermoFisher Scientific) was used to reveal the bands.

\section{Total RNA isolation and quantitative real-time PCR for small RNA-Seq}

Total RNA was isolated from epidermis and keratinocytes using Trizol ${ }^{\circledR}$ Reagent (Invitrogen, Carlsbad, CA) according to the manufacturer's instructions. RNA was quantified using a NanoDrop-1000 spectrophotometer (Peglab, Erlangen, Germany) and RNA quality monitored by an Agilent 2100 Bioanalyzer (Agilent, Böblingen, Germany). RNA was reverse transcribed to cDNA (Biorad, Hercules, CA, USA) and PIWIL-2 expression was quantified by RTPCR (Applied Biosystems 7500 Real-Time PCR System, Life Technologies, USA). Primers were designed using the Primer3 software. The PCR product was sequenced to prove specificity of the PCR.

\section{Small RNA-Seq}

Quality control of RNA samples was performed using the RNA 6000 Nano Kit (for total RNA) and smallRNA Kit (for small RNA species) on a 2100 Bioanalyzer (Agilent). Sequencing libraries were prepared at the Core facility Genomics, Medical University of Vienna using the NEBNext Multiplex Small RNA Library Prep Kit for Illumina according to the manufacturer's protocols (New England Biolabs). Libraries were QC checked for appropriate insert size on a Bioanalyzer 2100 using a High Sensitivity DNA Kit and quantitated using Qubit dsDNA HS Assay (Invitrogen). Pooled libraries had an average length of $150 \mathrm{bp}$ and were sequenced on a NextSeq500 instrument (Illumina) in
$1 \times 75$ bp sequencing mode. Reads with a read length $>5$ bp were adaptor trimmed and trimmed from the 3 '-end to a length of 50 bp using FASTQ Toolkit App from BaseSpace (illumina). The Small-RNA App from BaseSpace was used for read alignment against four reference databases (abundant, mature miRNA, other RNA, and genomic). The outputs contain hits to mature miRNAs, isomiRs, and piRNAs expressed as 'counts'.

\section{Total RNA isolation and quantitative real-time PCR (qPCR) for KC differentiation experiments}

Total RNA was isolated as described above and quantified using a NanoDrop-1000 spectrophotometer (Peglab, Erlangen, Germany). 200 ng RNA of each sample were reverse transcribed using iScript cDNA synthesis kit (Bio-Rad, Hercules, USA). Relative quantification was performed according to a previous publication [2] using the Light Cycler Master SYBR Green I kit (Roche Applied Science, Penzberg, Germany) on a Light Cycler 480 thermocycler. Primers were designed by Primer3 software (https://prime r3.ut.ee/) and synthesized by Microsynth AG (Vienna, Austria). Samples were normalized to beta-2-microglobulin as an internal reference gene and analyzed according to the $\Delta \Delta \mathrm{Ct}$ method as described by Pfaffl [36]. The following primers were used: beta-2-microglobulin 5'-GATGAGTAT GCCTGCCGTGTG-3' and 5'-CAATCCAAATGCGGCATC T-3'; Filaggrin 5'-AAGGTTCACATTTATTGCCAAA-3' and 5'-GGATTTGCCGAAATTCCTTT-3'; Loricrin 5'-GGA GTTGGAGGTGTTTTCCA-3' and 5'-ACTGGGGTTGGG AGGTAGTT-3'; Keratin 1 5'-ATCAATCTCGGTTGGATT CG-3' and 5'-TCCTGCTGCAAGTTGTCAAG-3'; Keratin 5 5'-CAAGCGTACCACTGCTGAGA-3' and 5'-TCAGCG ATGATGCTATCCAG-3'; Keratin 10 5'-GCTGACCTG GAGATGCAAAT- $3^{\prime}$ and $5^{\prime}$-AGCATCTTTGCGGTTTTG TT-3'; Keratin 14 5'-GACCATTGAGGACCTGAGGA-3' and 5'-GGCTCTCAATCTGCATCTCC-3'.

\section{Results}

\section{PIWIL-2 is regularly expressed in normal human skin}

Nuclei of KC in healthy human skin were weakly to moderately positive for PIWIL-2. The expression was mostly found in basal and suprabasal cells of the epidermis and was inhomogeneous (Fig. 1a), whereas the upper layer was mostly negative. The expression was negative in 3 of 26 samples, weak in 15 and moderate in another 8 samples. A weak and inconsistent staining was also found in the minority of nuclei of luminal cells of eccrine glands. In contrast, myoepithelial cells showed moderate cytoplasmic staining (Fig. 1b). Epithelial cells of the medulla of the hair were 

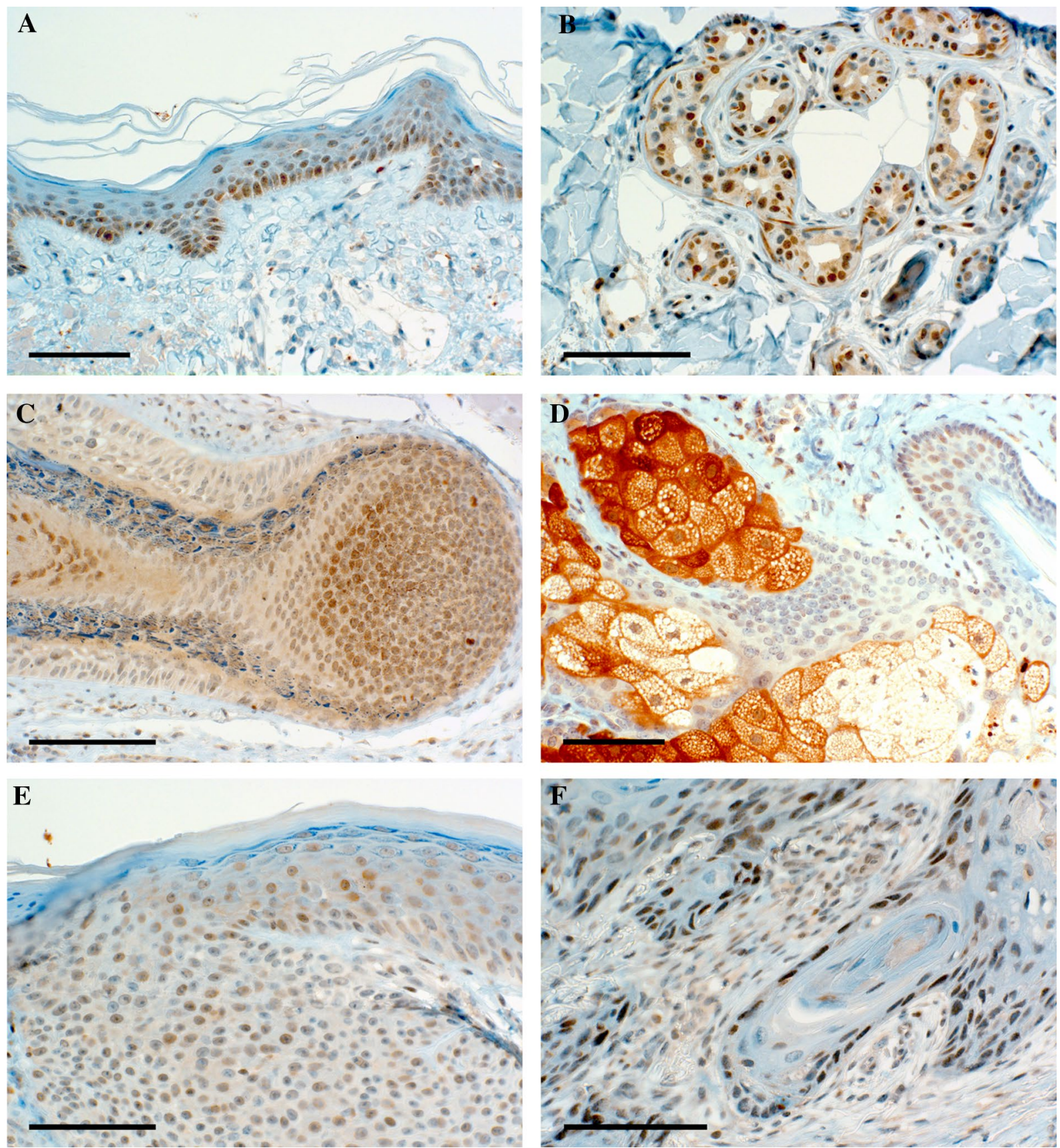

Fig. 1 PIWIL-2 expression in human skin. An example of regular human skin showing moderate staining intensity for PIWIL-2 of keratinocyte nuclei (a). The inhomogeneous expression was mostly found in basal and suprabasal epidermal cells, the staining expression was usually weaker than in this example. Luminal cells of eccrine glands also stained weakly and inconsistently. In contrast, myoepithelial cells showed moderate cytoplasmic staining (b). Epithelial cells of the hair follicle were mostly negative, whereas this example shows

inconsistently weakly to moderately reactive for PIWIL-2, whereas most other follicular epithelial cells were negative or rarely weakly reactive (Fig. 1c). The only cells of the skin with strong and consistent expression of PIWIL-2 were

weak to moderate reactivity for PIWIL-2 of the medulla (c). Strong and consistent expression of PIWIL-2 was found in mature sebocytes. In contrast, the basal layer of undifferentiated cells of sebaceous glands was negative to weakly positive (d). A basal cell carcinoma shows a staining intensity comparable to that of regular epidermal cells (e). Peripherally located undifferentiated cells of a squamous cell carcinoma stain moderately for PIWIL-2 (f). Scale bar $=100 \mu \mathrm{m}$

mature sebocytes. In contrast, the basal layer of undifferentiated cells of sebaceous glands was negative to weakly positive (Fig. 1d). Immunostaining was verified by RT-PCR 
showing specific PIWIL-2 mRNA expression in $\mathrm{KC}$ and the epidermis (data not shown).

Smooth muscle cells of both M. arrectores pilorum and the Tunica media of blood vessel showed moderate cytoplasmic staining (not shown).

\section{PIWIL-2 is not upregulated in basal cell carcinomas and squamous carcinomas of the skin}

PIWIL-2 overexpression has been reported to play a critical role in the development of a variety of carcinomas [14]. We investigated the expression of PIWIL-2 in 9 basal cell carcinomas. Five were negative, whereas four showed weak expression (Fig. 1e). There was no upregulation in comparison to non-neoplastic epidermis of the same specimen.

Similarly, there was no upregulation of PIWIL-2 in squamous cell carcinomas. In 9 of 16 samples, the expression was weaker and in 5 samples, the expression intensity was similar in comparison to non-neoplastic epidermis. Only two carcinomas showed a slight upregulation of PIWIL-2 (Fig. 1f). The expression was most prominent in peripherally located undifferentiated cells, but was also found in some mitotic figures and in parakeratotic nuclei.

\section{PIWIL-2 is expressed in murine and human epidermal KC and sebaceous glands}

Next, we investigated the expression of PIWIL-2 protein in murine preputial glands, i.e. the largest type of sebaceous glands of the mouse, and primary human and murine KC. In preputial glands, PIWIL-2 bands of $130 \mathrm{kD}$, corresponding to the full-length protein, and bands of 55 and $20 \mathrm{kD}$ were detected (Fig. 2a). Mouse KC (Fig. 2a) and testis (Fig. 2d) contained only PIWIL-2 protein species of 55-60 and $20 \mathrm{kD}$, whereas human KC showed bands with the size of $\sim 130 \mathrm{kD}$ corresponding to the full-length protein and only weak bands of smaller molecular weights, mainly at $60 \mathrm{kD}$. PIWIL-2 proteins of approximately 60 $\mathrm{kD}$ and $\sim 20 \mathrm{kD}$ (Fig. 2a) were reported previously to correspond to splice variants of PIWIL-2 [50]. Accordingly, primary KC in cell culture expressed PIWIL-2 consistently. In addition, PIWIL-2 was expressed in human endothelial cells [HUVECs (3/3) and HDMECs (1/1)], but not in the autonomously growing squamous cell carcinoma cell line A431 (0/2) (data not shown).

Treatment of human KC with a specific siRNA against PIWIL-2 led to the disappearance of the PIWIL-2 band on Western blots, validating the antibody against PIWIL-2 protein (Fig. 2b). siRNA-mediated depletion of PIWIL-2 did not impair growth and survival of the cells in vitro (data not shown).

When KC were induced to differentiate by maintaining them in confluent culture for up to 10 days [7], the expression of PIWIL-2 increased during the first 4 days and later decreased again (Fig. 2c). This pattern of regulation was found in three independent experiments, suggesting a consistent induction of PIWIL-2 expression during early KC differentiation and a repression at the late stages of $\mathrm{KC}$ differentiation. However, preliminary experiments showed that PIWIL-2 knockdown does not lead to a significant regulation of the KC differentiation markers keratin 1, 5, 10 and 14 as well as loricrin and filaggrin (supplementary information, Fig. 1) in monolayer cultures.

\section{Screening of piRNAs expressed in human KC and regulated during differentiation}

When investigating the expression of 3848 different piRNAs in human primary KC, we found 190 to be constitutively expressed using an arbitrary threshold of 10 counts in 6 samples consisting of undifferentiated and differentiated KC from 3 donors (Supplementary information, Table 1). 50 piRNAs were upregulated at least twofold (mean) in differentiating $\mathrm{KC}$ in three independent experiments (shown in Fig. 3). 29 of these 50 piRNAs showed a more than twofold upregulation in samples of all three donors and the average ratio was 4.19 . In contrast, only 15 piRNAs showed a downregulation in differentiating $\mathrm{KC}$ by less than half, 9 of those in samples from all the donors (Supplementary information, Table 2).

piRNAs can be derived from other RNAs including tRNAs [9, 23] and snoRNAs [54] and may regulate their function by homologue interaction. When comparing the sequence of 100 piRNAs with the strongest expression level to non-coding RNAs, we found 39 of them to be homologous to tRNAs, 27 to snoRNAs (SNORDs, mostly C/D-box snoRNAs) and 5 to miRNAs (Supplementary information, Table 3). Three of these five piRNAs were homologous to let7 and these were some of the piRNAs with the highest expression level.

Whereas only 4 of 39 piRNAs homologous to tRNAs showed homology to protein coding mRNAs, 18 piRNAs homologous to SNORDs showed homology to protein coding mRNAs (Supplementary information, Table 2).

Upregulated piRNAs were more likely to be homologous to SNORDs (29/50) than to tRNAs (13/50) and 21 of them were homologous to 16 different proteins. In contrast, downregulated piRNAs were rarely homologous to SNORDs $(1 / 15)$, or to tRNAs (3/15) and 3 of them were homologous to protein coding mRNAs.

piRNAs amplified by the ping-pong cycle are involved in transposon suppression and have been reported to have a uracil residue (U) at position 1 at their 5'-termini and an adenine residue (A) at position 10 [44]. Of 100 piRNAs with strongest expression in KC, 6 have been found to have this signature, whereas 29 had a U at their first position (Supplementary 


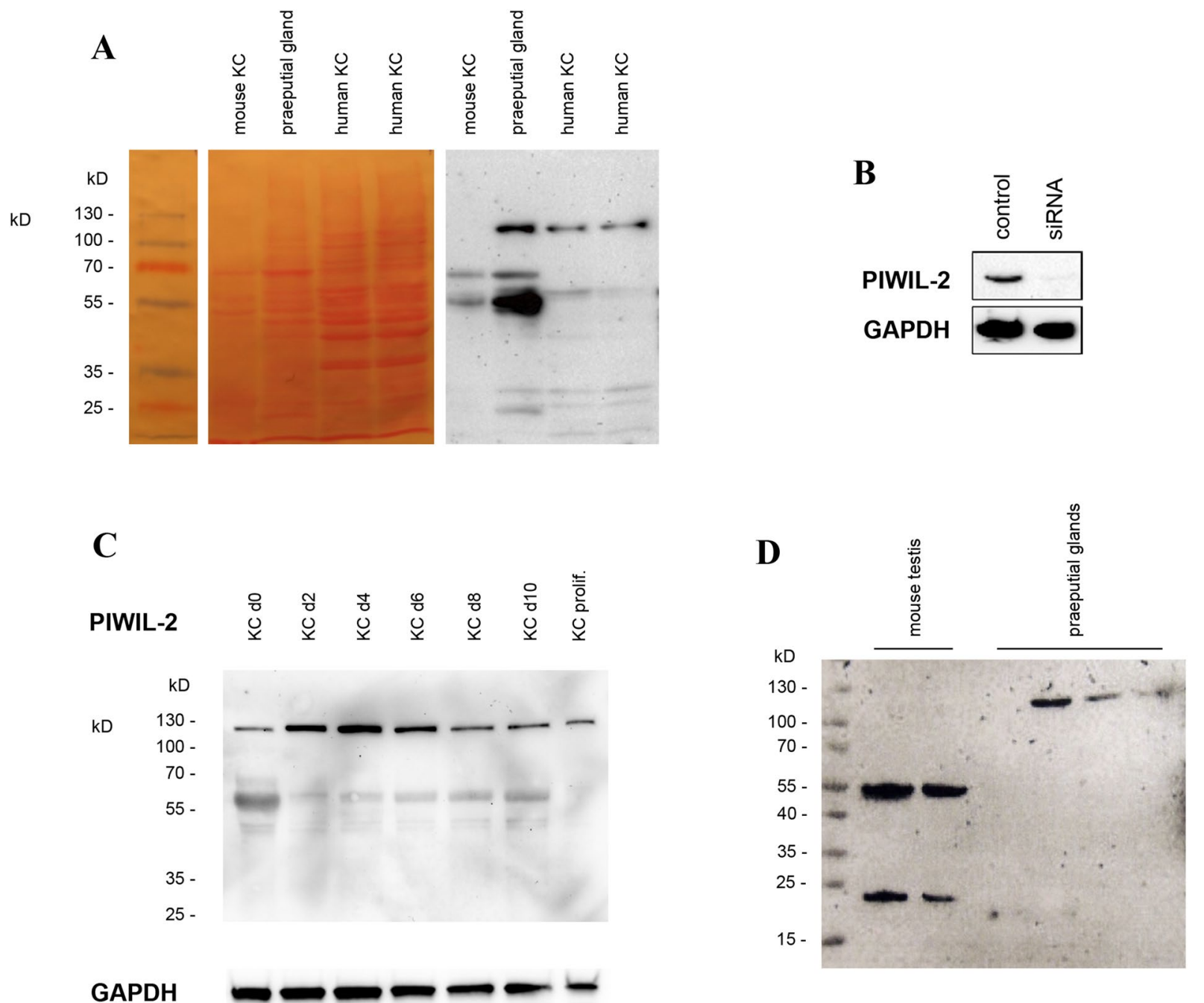

Fig. 2 PIWIL-2 expression in murine and human keratinocytes and sebaceous glands by Western blotting. a Mouse preputial glands showed $130 \mathrm{kD}$ PIWIL-2 bands, corresponding to the full-length protein as well as additional bands of $\sim 55-60$ and $20 \mathrm{kD}$ corresponding to splice variants. Mouse KCs contained only smaller PIWIL-2 protein species. Human KC showed bands $\sim 130 \mathrm{kD}$, corresponding to the full-length protein and only weak staining for smaller bands.

information, Table 3). 11 of 50 piRNAs upregulated in differentiating $\mathrm{KC}$ had a $\mathrm{U}$ at position 1, 3 of these in combination with an adenine at position 10.8 of the downregulated piRNAs had a $U$ at position 1 and 4 of these in combination with an adenine at position 10 . This distribution indicates a random frequency of these nucleotides. b Treatment of human KCs with a specific siRNA against PIWIL-2 led to the disappearance of the PIWIL-2 band on Western blots. $\mathbf{c}$ In $\mathrm{KC}$ induced to differentiate in confluent culture PIWIL-2 expression increased during the first 4 days and later decreased. $\mathbf{d}$ In contrast to mouse preputial glands, mouse testis contained only PIWIL-2 protein species of 60 and 20

Finally, PIWIL-2 knockdown resulted in the regulation of piRNAs in preliminary experiments (supplementary information, Fig. 1). 


\section{ratio in average number Discussion \\ differentiated KC of counts}

\begin{tabular}{|c|c|c|}
\hline piR-31970 & 14.57 & 18.17 \\
\hline piR-30840 & 8.67 & 145.00 \\
\hline piR-30318 & 8.17 & 18.33 \\
\hline piR-31762 & 7.31 & 18.00 \\
\hline piR-52729 & 6.87 & 19.67 \\
\hline piR-33748 & 6.68 & 28.17 \\
\hline piR-60238 & 5.97 & 40.67 \\
\hline piR-31531 & 5.93 & 476.17 \\
\hline piR-36712 & 5.84 & 71.83 \\
\hline piR-33687 & 5.67 & 10.00 \\
\hline piR-40982 & 5.23 & 570.50 \\
\hline piR-45371 & 5.20 & 10.33 \\
\hline piR-33650 & 4.94 & 521.83 \\
\hline piR-41004 & 4.91 & 33.50 \\
\hline piR-36169 & 4.77 & 12.50 \\
\hline piR-33686 & 4.65 & 64.00 \\
\hline piR-61919 & 4.61 & 4122.00 \\
\hline piR-30652 & 4.56 & 48.17 \\
\hline piR-30105 & 4.42 & 21.67 \\
\hline piR-36711 & 4.38 & 56.50 \\
\hline piR-30810 & 4.26 & 86.83 \\
\hline piR-36441 & 3.93 & 179.83 \\
\hline piR-35059 & 3.86 & 77.83 \\
\hline piR-32079 & 3.78 & 99.67 \\
\hline piR-31612 & 3.55 & 508.33 \\
\hline piR-31447 & 3.53 & 37.00 \\
\hline piR-34375 & 3.39 & 13.17 \\
\hline piR-34443 & 3.28 & 95.67 \\
\hline piR-35407 & 3.25 & 39.67 \\
\hline piR-34439 & 3.25 & 86.33 \\
\hline piR-57942 & 3.24 & 193.50 \\
\hline piR-53542 & 2.98 & 31.83 \\
\hline piR-34444 & 2.94 & 88.67 \\
\hline piR-34442 & 2.91 & 89.83 \\
\hline piR-34441 & 2.89 & 90.67 \\
\hline piR-61135 & 2.80 & 12.67 \\
\hline piR-34440 & 2.79 & 95.50 \\
\hline piR-36444 & 2.61 & 109.50 \\
\hline piR-36494 & 2.52 & 14.67 \\
\hline piR-36743 & 2.51 & 561.83 \\
\hline piR-36241 & 2.47 & 142.83 \\
\hline piR-30799 & 2.27 & 516.83 \\
\hline piR-36037 & 2.27 & 12.00 \\
\hline piR-43604 & 2.27 & 73.50 \\
\hline piR-36170 & 2.20 & 49.00 \\
\hline piR-36318 & 2.17 & 208.33 \\
\hline piR-57204 & 2.10 & 10.83 \\
\hline piR-36742 & 2.09 & 185.50 \\
\hline piR-36225 & 2.01 & 432.00 \\
\hline piR-34377 & 2.00 & 10.00 \\
\hline piR-36251 & 0.50 & 40.50 \\
\hline piR-54341 & 0.48 & 11.83 \\
\hline piR-36249 & 0.45 & 37.50 \\
\hline piR-36248 & 0.42 & 35.50 \\
\hline piR-49040 & 0.36 & 48.00 \\
\hline piR-33054 & 0.36 & 47.00 \\
\hline piR-38574 & 0.30 & 47.17 \\
\hline piR-36340 & 0.24 & 105.50 \\
\hline piR-36339 & 0.21 & 138.50 \\
\hline piR-60668 & 0.21 & 267.33 \\
\hline piR-38205 & 0.20 & 286.67 \\
\hline piR-34998 & 0.13 & 170.00 \\
\hline piR-52993 & 0.10 & 16.17 \\
\hline piR-52991 & 0.06 & 15.17 \\
\hline piR-52992 & 0.05 & 14.17 \\
\hline
\end{tabular}

Fig. 3 piRNAs expression is associated with the state of differentiated $\mathrm{KC}$. Whereas 50 piRNAs were upregulated at least twofold (mean) in differentiating KC, 15 piRNAs showed a downregulation in differentiating $\mathrm{KC}$ by less than half

In this study, we describe that PIWIL-2 is regularly expressed in epidermal KC, epithelial cells of skin appendages as well as in mesenchymal cells. Our results are complementary to a variety of previous studies that do not show any PIWIL-2 expression in adult tissues [25, 45].

PIWIL-2 has been shown to be expressed in human germ cells and to play a role in maintaining genomic integrity by suppression of transposon activity [38]. In contrast, a possible function of PIWIL-2 protein and piRNA expression in $\mathrm{KC}$ and skin appendages has not yet been investigated. Similar to their activity in germ cells, PIWIL-2 and piRNAs could act on transposons and retroviruses in the skin. However, the very small number of piRNAs expressed in KC in vitro argues against a role in post-transcriptional control of a large variety of transposable elements (TE). Our results match those of a previous study showing that the population of piRNAs present in Hela cells is dramatically small in contrast to the enormous population of known piRNAs in male germ cells [31].

PIWIL-2 expression has been shown to be associated with stem cell properties and has been regarded as a potential neoplasia biomarker [41, 42, 53]. Intriguingly, we could demonstrate that in adult skin, PIWIL-2 is not predominantly expressed in compartments with possible stem cell populations in the epidermis. In fact, we even detected PIWIL-2 expression in differentiated sebocytes. Since c-MYC can be induced by PIWIL-2 in epithelial cells [49] and its overexpression stimulates differentiation in sebaceous glands [47], the observed strong PIWIL-2 expression may indicate that this protein is involved in sebocyte differentiation.

PIWI proteins are associated with chromatin remodeling by histone acetylation and methylation [11, 25, 27, 46, 52], and PIWI deficiency has been shown to drastically change the epigenetic landscape in Drosophila [18]. Accordingly, PIWIL-2 could be involved in KC proliferation and differentiation dependent somatic gene regulation. Strikingly, we did not observe altered expression of important $\mathrm{KC}$ differentiation markers. However, since $\mathrm{KC}$ in monolayer cultures do not fully differentiate, other, more sophisticated models, such as in vitro skin models or knock-out animals, would be necessary to address this question.

Recently, a role of PIWIL-2 in the repair of UV-induced DNA damage was identified by showing that UV irradiated mouse fibroblasts lacking PIWIL-2 protein expression were more susceptible to apoptosis [52]. However, we were not able to show a regulation of PIWIL-2 neither by UV-A nor by UV-B radiation in human KC (not shown).

Whereas PIWIL-2 upregulation has been described in precancerous stem cells [29] and in several malignant neoplasms $[27,37]$ suggesting a role in tumor initiation, we did 
not find a distinct upregulation of this protein in epithelial skin tumors. In contrast, we found a variety of piRNAs to be expressed in KC from healthy skin. Of 190 piRNAs identified in $\mathrm{KC}$ in this study, 33 have previously been described to be expressed in squamous epithelial cells [24] supporting the specificity of our findings. Presently, the significance of piRNA originating outside of transposable elements is largely unknown and piRNAs have already been shown to play a crucial role in host gene regulation [38]. In line with these publications our results suggest that piRNAs are also involved in epigenetic processes in adult epithelia [35].

Apart from homology to a variety of protein coding mRNAs, piRNAs identified in this study were homologous to miRNAs, i.e. let7 and miR-182, SNORDs and tRNAs. A major function of let7 genes may be to promote terminal differentiation $[8,10]$ and a recent study has identified let7 as a key mediator linking stemness genes with Lin28 in squamous cells also [4]. In addition, miR-182 has multiple roles in differentiation, development, and functional maintenance $[6,48]$. The strong expression of let7 and miR-182 homologous piRNAs in comparison to other piRNAs indicates a role of these ncRNAs in the regulation of stemness and differentiation in $\mathrm{KC}$, however, their exact function has still to be determined. Small nucleolar RNAs (snoRNAs) are known to target 2'-O-methylation of rRNAs. Since SNORDs [9] have been shown to be precursors of piRNAs [54], they may function as gene expression modulators $[9,43]$. We also found the expression of abundant tRNA-derived small RNA (tsRNAs) in primary KC. Since some tsRNAs match known piRNA sequences and can be bound by the PIWI proteins, tsRNAs might also be involved in gene regulation [23].

In summary, we find PIWIL-2 and piRNAs to be constitutively expressed in the skin and $\mathrm{KC}$ in vitro. Our finding that PIWIL-2 expression is associated with the degree of differentiation in $\mathrm{KC}$ cultures and that a multitude of piRNAs is distinctly regulated in the context of $\mathrm{KC}$ differentiation suggests a role of somatic gene regulation by PIWI-piRNA pathways both in the epidermis and appendages of the skin. In contrast, no upregulation of PIWIL-2 in carcinomas was found. Our analysis of piRNAs expressed in non-differentiated and differentiated $\mathrm{KC}$ builds a basis for further studies investigating the role of these piRNAs in KC differentiation and epithelial homeostasis.

Acknowledgements Open access funding provided by Medical University of Vienna.

\section{Compliance with ethical standards}

Conflict of interest The authors have no conflict of interest to declare.

Open Access This article is licensed under a Creative Commons Attribution 4.0 International License, which permits use, sharing, adaptation, distribution and reproduction in any medium or format, as long as you give appropriate credit to the original author(s) and the source, provide a link to the Creative Commons licence, and indicate if changes were made. The images or other third party material in this article are included in the article's Creative Commons licence, unless indicated otherwise in a credit line to the material. If material is not included in the article's Creative Commons licence and your intended use is not permitted by statutory regulation or exceeds the permitted use, you will need to obtain permission directly from the copyright holder. To view a copy of this licence, visit http://creativecommons.org/licenses/by/4.0/.

\section{References}

1. Aravin A, Gaidatzis D, Pfeffer S, Lagos-Quintana M, Landgraf P, Iovino N, Morris P, Brownstein MJ, Kuramochi-Miyagawa S, Nakano T, Chien M, Russo JJ, Ju J, Sheridan R, Sander C, Zavolan M, Tuschl T (2006) A novel class of small RNAs bind to MILI protein in mouse testes. Nature 442:203-207. https://doi. org/10.1038/nature04916

2. Beer L, Mlitz V, Gschwandtner M, Berger T, Narzt MS, Gruber F, Brunner PM, Tschachler E, Mildner M (2015) Bioinformatics approach for choosing the correct reference genes when studying gene expression in human keratinocytes. Exp Dermatol 24:742747. https://doi.org/10.1111/exd.12759

3. Botchkareva NV (2017) The molecular revolution in cutaneous biology: noncoding RNAs: new molecular players in dermatology and cutaneous biology. J Invest Dermatol 137:e105-e111. https:// doi.org/10.1016/j.jid.2017.02.001

4. Chien CS, Wang ML, Chu PY, Chang YL, Liu WH, Yu CC, Lan YT, Huang PI, Lee YY, Chen YW, Lo WL, Chiou SH (2015) Lin28B/Let-7 regulates expression of Oct4 and Sox 2 and reprograms oral squamous cell carcinoma cells to a stem-like state. Cancer Res 75:2553-2565. https://doi.org/10.1158/0008-5472. CAN-14-2215

5. Consortium TR (2017) RNAcentral: a comprehensive database of non-coding RNA sequences. Nucleic Acids Res 45:D128-D134. https://doi.org/10.1093/nar/gkw1008

6. Dong MJ, Xiao T, Meng W, Hu F (2016) Research progress in the function of microRNA-182. Sheng Li Xue Bao 68:107-113

7. Eckhart L, Declercq W, Ban J, Rendl M, Lengauer B, Mayer C, Lippens S, Vandenabeele P, Tschachler E (2000) Terminal differentiation of human keratinocytes and stratum corneum formation is associated with caspase-14 activation. J Invest Dermatol 115:1148-1151. https://doi.org/10.1046/j.1523-1747.2000.00205 . $\mathrm{x}$

8. Esquela-Kerscher A, Slack FJ (2006) Oncomirs-microRNAs with a role in cancer. Nat Rev Cancer 6:259-269. https://doi. org/10.1038/nrc1840

9. Falaleeva M, Stamm S (2013) Processing of snoRNAs as a new source of regulatory non-coding RNAs: snoRNA fragments form a new class of functional RNAs. BioEssays 35:46-54. https://doi. org/10.1002/bies.201200117

10. Farzaneh M, Attari F, Khoshnam SE (2017) Concise review: LIN28/let-7 signaling, a critical double-negative feedback loop during pluripotency reprogramming, and tumorigenicity. Cell Reprogram 19:289-293. https://doi.org/10.1089/cell.2017.0015

11. Feng D, Yan K, Zhou Y, Liang H, Liang J, Zhao W, Dong Z, Ling B (2016) Piwil2 is reactivated by HPV oncoproteins and initiates cell reprogramming via epigenetic regulation during cervical cancer tumorigenesis. Oncotarget 7:64575-64588. https://doi. org/10.18632/oncotarget.11810

12. Fuchs E (2016) Epithelial skin biology: three decades of developmental biology, a hundred questions answered and a thousand new ones to address. Curr Top Dev Biol 116:357-374. https://doi. org/10.1016/bs.ctdb.2015.11.033 
13. Gschwandtner M, Paulitschke V, Mildner M, Brunner PM, Hacker S, Eisenwort G, Sperr WR, Valent P, Gerner C, Tschachler E (2017) Proteome analysis identifies L1CAM/CD171 and DPP4/ CD26 as novel markers of human skin mast cells. Allergy 72:8597. https://doi.org/10.1111/all.12919

14. Han YN, Li Y, Xia SQ, Zhang YY, Zheng JH, Li W (2017) PIWI proteins and PIWI-interacting RNA: emerging roles in cancer. Cell Physiol Biochem 44:1-20. https://doi.org/10.1159/00048 4541

15. He G, Chen L, Ye Y, Xiao Y, Hua K, Jarjoura D, Nakano T, Barsky SH, Shen R, Gao JX (2010) Piwil2 expressed in various stages of cervical neoplasia is a potential complementary marker for p16. Am J Transl Res 2:156-169

16. He W, Wang Z, Wang Q, Fan Q, Shou C, Wang J, Giercksky KE, Nesland JM, Suo Z (2009) Expression of HIWI in human esophageal squamous cell carcinoma is significantly associated with poorer prognosis. BMC Cancer 9:426. https://doi. org/10.1186/1471-2407-9-426

17. Herter EK, Xu Landen N (2017) Non-coding RNAs: new players in skin wound healing. Adv Wound Care (New Rochelle) 6:93107. https://doi.org/10.1089/wound.2016.0711

18. Huang XA, Yin H, Sweeney S, Raha D, Snyder M, Lin H (2013) A major epigenetic programming mechanism guided by piRNAs. Dev Cell 24:502-516. https://doi.org/10.1016/j.devce 1.2013.01.023

19. Iwasaki YW, Murano K, Ishizu H, Shibuya A, Iyoda Y, Siomi MC, Siomi H, Saito K (2016) Piwi modulates chromatin accessibility by regulating multiple factors including histone $\mathrm{H} 1$ to repress transposons. Mol Cell 63:408-419. https://doi.org/10.1016/j. molcel.2016.06.008

20. Iwasaki YW, Siomi MC, Siomi H (2015) PIWI-Interacting RNA: its biogenesis and functions. Annu Rev Biochem 84:405-433. https://doi.org/10.1146/annurev-biochem-060614-034258

21. Juliano C, Wang J, Lin H (2011) Uniting germline and stem cells: the function of Piwi proteins and the piRNA pathway in diverse organisms. Annu Rev Genet 45:447-469. https://doi.org/10.1146/ annurev-genet-110410-132541

22. Kalantari R, Chiang CM, Corey DR (2016) Regulation of mammalian transcription and splicing by Nuclear RNAi. Nucleic Acids Res 44:524-537. https://doi.org/10.1093/nar/gkv1305

23. Keam SP, Young PE, McCorkindale AL, Dang TH, Clancy JL, Humphreys DT, Preiss T, Hutvagner G, Martin DI, Cropley JE, Suter CM (2014) The human Piwi protein Hiwi2 associates with tRNA-derived piRNAs in somatic cells. Nucleic Acids Res 42:8984-8995. https://doi.org/10.1093/nar/gku620

24. Krishnan AR, Korrapati A, Zou AE, Qu Y, Wang XQ, Califano JA, Wang-Rodriguez J, Lippman SM, Hovell MF, Ongkeko WM (2017) Smoking status regulates a novel panel of PIWI-interacting RNAs in head and neck squamous cell carcinoma. Oral Oncol 65:68-75. https://doi.org/10.1016/j.oraloncology.2016.12.022

25. Kuramochi-Miyagawa S, Watanabe T, Gotoh K, Totoki Y, Toyoda A, Ikawa M, Asada N, Kojima K, Yamaguchi Y, Ijiri TW, Hata K, Li E, Matsuda Y, Kimura T, Okabe M, Sakaki Y, Sasaki H, Nakano T (2008) DNA methylation of retrotransposon genes is regulated by Piwi family members MILI and MIWI2 in murine fetal testes. Genes Dev 22:908-917. https://doi.org/10.1101/ gad. 1640708

26. Lee EJ, Banerjee S, Zhou H, Jammalamadaka A, Arcila M, Manjunath BS, Kosik KS (2011) Identification of piRNAs in the central nervous system. RNA 17:1090-1099. https://doi.org/10.1261/ rna.2565011

27. Lee JH, Schutte D, Wulf G, Fuzesi L, Radzun HJ, Schweyer S, Engel W, Nayernia K (2006) Stem-cell protein Piwil2 is widely expressed in tumors and inhibits apoptosis through activation of Stat3/Bcl-XL pathway. Hum Mol Genet 15:201-211. https://doi. org/10.1093/hmg/ddi430
28. Li LC (2014) Chromatin remodeling by the small RNA machinery in mammalian cells. Epigenetics 9:45-52. https://doi.org/10.4161/ epi. 26830

29. Liu W, Gao Q, Chen K, Xue X, Li M, Chen Q, Zhu G, Gao Y (2014) Hiwi facilitates chemoresistance as a cancer stem cell marker in cervical cancer. Oncol Rep 32:1853-1860. https://doi. org/10.3892/or.2014.3401

30. Lopez-Pajares V, Qu K, Zhang J, Webster DE, Barajas BC, Siprashvili Z, Zarnegar BJ, Boxer LD, Rios EJ, Tao S, Kretz M, Khavari PA (2015) A LncRNA-MAF:MAFB transcription factor network regulates epidermal differentiation. Dev Cell 32:693-706. https://doi.org/10.1016/j.devcel.2015.01.028

31. Lu Y, Li C, Zhang K, Sun H, Tao D, Liu Y, Zhang S, Ma Y (2010) Identification of piRNAs in Hela cells by massive parallel sequencing. BMB Rep 43:635-641. https://doi.org/10.5483/ BMBRep.2010.43.9.635

32. Ng KW, Anderson C, Marshall EA, Minatel BC, Enfield KS, Saprunoff HL, Lam WL, Martinez VD (2016) Piwi-interacting RNAs in cancer: emerging functions and clinical utility. Mol Cancer 15:5. https://doi.org/10.1186/s12943-016-0491-9

33. Pammer J, Cross HS, Frobert Y, Tschachler E, Oberhuber G (2000) The pattern of prion-related protein expression in the gastrointestinal tract. Virchows Arch 436:466-472

34. Pammer J, Weninger W, Tschachler E (1998) Human keratinocytes express cellular prion-related protein in vitro and during inflammatory skin diseases. Am J Pathol 153:1353-1358. https ://doi.org/10.1016/S0002-9440(10)65720-3

35. Peng JC, Lin H (2013) Beyond transposons: the epigenetic and somatic functions of the Piwi-piRNA mechanism. Curr Opin Cell Biol 25:190-194. https://doi.org/10.1016/j.ceb.2013.01.010

36. Pfaffl MW, Tichopad A, Prgomet C, Neuvians TP (2004) Determination of stable housekeeping genes, differentially regulated target genes and sample integrity: BestKeeper-Excel-based tool using pair-wise correlations. Biotechnol Lett 26:509-515

37. Qu X, Liu J, Zhong X, Li X, Zhang Q (2015) PIWIL2 promotes progression of non-small cell lung cancer by inducing CDK2 and cyclin A expression. J Transl Med 13:301. https://doi.org/10.1186/ s12967-015-0666-y

38. Robine N, Lau NC, Balla S, Jin Z, Okamura K, KuramochiMiyagawa S, Blower MD, Lai EC (2009) A broadly conserved pathway generates 3'UTR-directed primary piRNAs. Curr Biol 19:2066-2076. https://doi.org/10.1016/j.cub.2009.11.064

39. Ross RJ, Weiner MM, Lin H (2014) PIWI proteins and PIWIinteracting RNAs in the soma. Nature 505:353-359. https://doi. org/10.1038/nature12987

40. Sato K, Siomi MC (2013) Piwi-interacting RNAs: biological functions and biogenesis. Essays Biochem 54:39-52. https://doi. org/10.1042/bse0540039

41. Shahali M, Kabir-Salmani M, Nayernia K, Soleimanpour-Lichaei HR, Vasei M, Mowla SJ, Ranaie E, Shakibaie M, Modaresi MH (2013) A novel in vitro model for cancer stem cell culture using ectopically expressed piwil2 stable cell line. Cell J 15:250-257

42. Sharma AK, Nelson MC, Brandt JE, Wessman M, Mahmud N, Weller KP, Hoffman R (2001) Human CD34(+) stem cells express the hiwi gene, a human homologue of the Drosophila gene piwi. Blood 97:426-434

43. Stepanov GA, Filippova JA, Nushtaeva AA, Kuligina EV, Koval OA, Richter VA, Semenov DV (2016) Artificial analogues of circulating box C/D RNAs induce strong innate immune response and microRNA activation in human adenocarcinoma cells. Adv Exp Med Biol 924:121-125. https://doi.org/10.1007/978-3-31942044-8_24

44. Toth KF, Pezic D, Stuwe E, Webster A (2016) The piRNA pathway guards the germline genome against transposable elements. Adv Exp Med Biol 886:51-77. https://doi. org/10.1007/978-94-017-7417-8_4 
45. Unhavaithaya Y, Hao Y, Beyret E, Yin H, Kuramochi-Miyagawa S, Nakano T, Lin H (2009) MILI, a PIWI-interacting RNA-binding protein, is required for germ line stem cell self-renewal and appears to positively regulate translation. J Biol Chem 284:65076519. https://doi.org/10.1074/jbc.M809104200

46. Wang QE, Han C, Milum K, Wani AA (2011) Stem cell protein Piwil2 modulates chromatin modifications upon cisplatin treatment. Mutat Res 708:59-68. https://doi.org/10.1016/j.mrfmm m.2011.02.001

47. Watt FM, Frye M, Benitah SA (2008) MYC in mammalian epidermis: how can an oncogene stimulate differentiation? Nat Rev Cancer 8:234-242. https://doi.org/10.1038/nrc2328

48. Wei Q, Lei R, Hu G (2015) Roles of miR-182 in sensory organ development and cancer. Thorac Cancer 6:2-9. https://doi. org/10.1111/1759-7714.12164

49. Yao Y, Li C, Zhou X, Zhang Y, Lu Y, Chen J, Zheng X, Tao D, Liu Y, Ma Y (2014) PIWIL2 induces c-Myc expression by interacting with NME2 and regulates c-Myc-mediated tumor cell proliferation. Oncotarget 5:8466-8477. https://doi.org/10.18632/ oncotarget.2327

50. Ye Y, Yin DT, Chen L, Zhou Q, Shen R, He G, Yan Q, Tong Z, Issekutz AC, Shapiro CL, Barsky SH, Lin H, Li JJ, Gao JX (2010) Identification of Piwil2-like (PL2L) proteins that promote tumorigenesis. PLoS ONE 5:e13406. https://doi.org/10.1371/journ al.pone.0013406
51. Yi R, Poy MN, Stoffel M, Fuchs E (2008) A skin microRNA promotes differentiation by repressing 'stemness'. Nature 452:225229. https://doi.org/10.1038/nature06642

52. Yin DT, Wang Q, Chen L, Liu MY, Han C, Yan Q, Shen R, He G, Duan W, Li JJ, Wani A, Gao JX (2011) Germline stem cell gene PIWIL2 mediates DNA repair through relaxation of chromatin. PLoS ONE 6:e27154. https://doi.org/10.1371/journal.pone.00271 54

53. Zhang D, Wu X, Liu X, Cai C, Zeng G, Rohozinski J, Zhang Y, Wei G, He D (2017) Piwil2-transfected human fibroblasts are cancer stem cell-like and genetically unstable. Oncotarget 8:12259-12271. https://doi.org/10.18632/oncotarget.14696

54. Zhong F, Zhou N, Wu K, Guo Y, Tan W, Zhang H, Zhang X, Geng G, Pan T, Luo H, Zhang Y, Xu Z, Liu J, Liu B, Gao W, Liu C, Ren L, Li J, Zhou J, Zhang H (2015) A SnoRNA-derived piRNA interacts with human interleukin-4 pre-mRNA and induces its decay in nuclear exosomes. Nucleic Acids Res 43:10474-10491. https ://doi.org/10.1093/nar/gkv954

Publisher's Note Springer Nature remains neutral with regard to jurisdictional claims in published maps and institutional affiliations. 